\title{
PSICOPATOLOGIA, EXOTISMO E DIVERSIDADE: ENSAIO DE ANTROPOLOGIA DA PSICOPATOLOGIA
}

Adriano Holanda

\begin{abstract}
RESUMO. O texto se propõe a uma reflexão em torno de uma perspectiva antropológica da questão da psicopatologia. Partindo da análise antropológica de Tzvetan Todorov, perpassa o ensaio histórico de Theodore Zeldin, alcançando a crítica de Thomas Szasz e a abordagem histórico-antropológica de Michel Foucault, na tentativa de clarear a compreensão do fenômeno psicopatológico. Nesta perspectiva crítico-histórica, a psicopatologia é vista como um fenômeno contextualizado, inserido na construção das mentalidades específicas da cultura ocidental.
\end{abstract}

Palavras-chave: psicopatologia, exotismo, diversidade.

\section{PSYCHOPATHOLOGY, EXOTICISM AND DIVERSITY: SOME REMARKS ON THE ANTHROPOLOGY OF PSYCHOPATHOLOGY}

\begin{abstract}
The purpose of this paper is to reflect upon an anthropological approach of psychopathology. It intends to throw some light upon the phenomenon of the "psychopathologic". It begins with some remarks on the anthropological concept of Tzevan Todorov. It also analyses Theodore Zeldin's historical essay, Thomas Szasz's critical reflections and Michel Foucault's historic-anthropological approach. In this historical perspective, "Psychopathology" is conceived as a rather contextualized phenomenon, part of the specific mentalities constructed by the Western culture.
\end{abstract}

Key words: psychopathology, exotic, diversity.

\section{INTRODUÇÃO}

O campo da Psicopatologia é difícil de se delimitar. Seja numa concepção de polaridade normalanormal, seja como campo específico de ação clínica, seu terreno é cercado de imprecisões e de opiniões divergentes. Psicopatologia e Psiquiatria, por exemplo, se confundem comumente. Isto invariavelmente leva a uma compreensão limitada do próprio fenômeno psicopatológico. No campo específico da Psicopatologia, uma obra considerada "fundante" é o Psicopatologia Geral, de Karl Jaspers, publicada em 1911, portanto, anterior mesmo ao conceito de esquizofrenia, cunhado por Bleuler, em 1913.

Além de ser fundamento, é também uma obra que inaugura uma nova forma de estudo: uma psicopatologia fenomenológica, preocupada inicialmente com a descrição das significações do fenômeno psicopatológico.

Não obstante, o campo da Psicopatologia é anterior a Jaspers. Ao traçar o histórico da questão, esbarramos em algumas imprecisões. Alguns (Corsini, 1984; Bonin, 1991) afirmam que o primeiro a falar em "psicopatologia" foi Théodule Ribot (1839-1916), em 1881. Outros, como Paim (1993), afirmam que a psicopatologia se iniciou com Esquirol e Griesinger. É certo, contudo, que a primeira cátedra desta matéria só surge em 1905, com Georges Dumas, aluno de Ribot. Nesta época era comum a denominação "Psicologia Patológica" ou "Psicologia Anormal", para o que viria a ser, futuramente, a Psiquiatria. Convém, todavia, não confundir o campo da "psicopatologia" com o da "psiquiatria". Como assinala Paim (1993,1), o campo

Psicólogo, Mestre em Psicologia Clínica pela Universidade de Brasília (UnB). Doutorando em Psicologia pela Pontifícia Universidade Católica de Campinas (PUC-Campinas). Professor dos Cursos de Psicologia da UNIP e Universidade São Marcos. Autor do livro Diálogo e Psicoterapia. Correlações entre Carl Rogers e Martin Buber (Lemos Editorial). Co-Organizador do livro Psicologia e Pesquisa Fenomenológica. Reflexões e Perspectivas (Editora Ômega).

Endereço para correspondência: Av. Marechal Carmona, 494, Ap. 24. V. J. Jorge, Cep 13035.510, Campinas/SP. E-mail: aholanda@yahoo.com 
de estudo da psicopatologia é mais restrito do que o da psiquiatria, e “... se limita ao estudo dos fenômenos anormais da vida mental e tem como método $a$ fenomenologia".

Segundo Paim (1993), os primórdios da psicopatologia estão nas obras de Jean-Étienne Esquirol, com o livro Traité des Maladies Mentales, de 1838, e de Wilhelm Griesinger, que publica Patologia e Terapêutica das Enfermidades Psíquicas, em $1845^{1}$. Além disso, segundo o autor, Esquirol teria sido o primeiro professor da especialidade, em 1817. Assim, não seriam nem Moreau de Tours, nem Théodule Ribot os "fundadores" da psicopatologia. Em adição a isto, Paim (1993) ressalta que importantes obras, como o Tratado da Loucura, de Batt - publicado em 1758 -; o Tratado médico analítico da loucura em geral e em particular, de Vicenzo Chiarugi, de 1794 e mesmo o Traité MédicoPhilosophique, de Pinel, de 1801, ainda não continham os elementos que seriam os germens da psicopatologia.

A evolução da psicopatologia perpassa trabalhos importantes da Psicologia Médica, tais como os de Ernst Kretschmer, em 1954 ou as Vinte Aulas de Psicologia Médica de Georges Jean-Baptiste Heuyer, de 1966. Algumas obras de destaque, contudo, não se referem especificamente ao termo "psicopatologia", como é o caso do famoso Manual de Psiquiatria, de Henri Ey, publicado originalmente em 1963 (Van den Berg, 1966; Coleman, 1977; Paim, 1993; Morel, 1997).

Já Eugène Minkowski, em seu clássico Traité de Psychopathologie, de 1966, pretende realizar uma "ciência antropológica", tomando por base o homem a partir do inter-humano. Minkowski (1995) critica a "psicopatologia geral" dos manuais como sendo apenas uma descrição sintomatológica, sem indicações das significações destes fenômenos. Vale ressaltar que sintoma significa "indicador de" ou "significante". Assim, Minkowski termina por recomendar uma "psicopatologia sindrômica" ao contrário de uma psicopatologia tradicional, calcada na descrição isolada dos distúrbios.

A psicopatologia se converteu na intermediária obrigatória entre a psiquiatria e a filosofia, sem por isso confundir-se nem com uma nem com outra. Mas se encontra mais próxima da filosofia do que pensava seu iniciador Ribot, tanto que a psiquiatria se

Ey; Bernard \& Brisset (1987) localizam a publicação deste livro mais cedo, em 1843 , e sua primeira tradução para o francês em 1865 . distanciou mais dela do que previa Pinel, seu ilustre fundador (Thuilleaux, citado por Ionescu, 1994, p. 10).

Como se percebe, o terreno da psicopatologia ainda permanece obscuro e cercado de mitologias e incompreensões. Além de uma perspectiva genética da construção de um pensamento psicopatológico (se associada ou não à Psiquiatria, à Filosofia ou mesmo à Psicologia), para compreendermos o fenômeno psicopatológico, é necessário perpassarmos uma circunscrição histórica de seu conceito, bem como uma diferenciação mínima entre os campos.

Tizón (1978) define a "psiquiatria" como a disciplina médica - instrumental - que estuda e trata as pessoas que apresentam condutas "anômalas", como um conjunto de tecnologias baseadas numa série de conhecimentos teóricos (oriundos de ciências diversas); enquanto a "psicopatologia" seria o campo de estudo da "psicologia do anômalo ou do transtornado". O autor define assim a psiquiatria como sendo uma "psicopatologia aplicada".

Para Karl Jaspers (1987), a Psiquiatria seria a profissão prática, enquanto a "psicopatologia" seria a ciência em si. Já Ludwig Binswanger assinala que a psicopatologia deve ser fenomenológica, visto que o "psicopatologista" deve encaixar as manifestações do doente num contexto geral (Sonnenreich \& Bassit, 1979).

Binswanger (1977) - na mesma direção apontada por Minkowski - procura apresentar uma visão "antropológica" da psicopatologia. Por "antropologia" entendemos a ciência da totalidade do fenômeno humano.

Uma visão antropológica da psicopatologia implica, pois, na compreensão das modalidades existenciais dos pacientes, no intuito de elucidar os sentidos dos seus sintomas. Nesta perspectiva, a doença mental é um fenômeno biográfico, passível de interpretação "fenomenológico-antropológica" (Binswanger, 1977). Parte das descrições clínicopsiquiátricas dos sintomas, para alcançar a compreensão das transformações e formas existenciais, das quais se extraem as condições de possibilidade do sujeito humano.

Nesta "visão antropológica" da psicopatologia, Binswanger (1977) propõe retirar a compreensão da doença do "juízo médico" (baseado em valores biológicos) - e, portanto, destacá-la da perspectiva simplesmente psiquiátrica - e do "estado-de-coisas" médico-psiquiátrico, para alcançar um quadro mais amplo da estrutura existencial do sujeito humano, visto que "a interrogação antropológica não pode jamais se limitar a uma só direção de ser, mas 
justamente por que antropológica, conserva sempre presente a estrutura total do ser-homem" (Binswanger, 1971, p.237).

Neste sentido, procuraremos entender a "psicopatologia" enquanto um fenômeno, enquanto uma manifestação humana, representativa dos "modos-de-ser" deste humano. Nesta direção, cremos que a psicopatologia transcende as relações conceituais, tornando-se um modo de apreensão do humano.

$\mathrm{Na}$ expectativa desta consideração, procuraremos encontrar similaridades entre este fenômeno e as diversas possibilidades de manifestação do humano, aqui representadas pela "diversidade" - ou seja, pela multiplicidade dos "modos-de-ser" humanos - e por uma especificidade destes "modos-de-ser", igualmente cercada de obscuridades, que é o "exotismo", para, a partir de uma visão antropológica, esboçar uma outra forma de refletir sobre a noção do patológico.

\section{PSICOPATOLOGIA, EXOTISMO E DIVERSIDADE - HISTÓRIA E ANTROPOLOGIA}

A diversidade humana talvez seja uma das questões mais cruciais e mais difíceis de ser compreendidas. Esta diversidade foi - e ainda é muitas vezes a própria responsável pela discriminação e pelo estigma. Lidar com a diversidade é, pois, lidar com a diferença - o "alter", o "divergente" - e ao mesmo tempo com a semelhança - o "similar", o "correspondente".

Ora, a identificação do "traço patológico" é algo inerente à realidade humana. É o modo de adaptação que reside entre o "normal" e o "patológico". Por "traço patológico" pretendemos designar aquilo que há de similar na natureza humana que se aproxima do fenômeno considerado "patológico". Similitude e diferença. Proximidade e diversidade. Eis a questão.

A história está repleta de exemplos de segregação do diverso, produto da dificuldade em se estabelecer contato íntimo com a similaridade da diferença (ou com a diferença do similar), bem como de numerosas situações onde o similar é preferido ao cotidiano. Theodore Zeldin, num excelente ensaio histórico, afirma que a "nossa imaginação é habitada por fantasmas" e que a "mente é um refúgio de idéias que datam de muitos e diferentes séculos(...)" (Zeldin, 1996, p.7).

Ao elaborar questões em torno de "como os seres humanos continuam a perder as esperanças, e como novos encontros, e óculos novos, as renovam", Zeldin (1996, p.9) traz à tona a realidade total da humanidade: totalidade na diversidade, inseparabilidade enquanto identificação na similitude.

Podemos principiar fazendo uma analogia entre a psicopatologia como "fenômeno" e a "escravidão".

O pior sentimento de fracasso seria concluir que não se viveu em absoluto, não se foi tido como ser humano independente, jamais se foi ouvido, nunca se foi instado a opinar, mas olhado como bem móvel, como propriedade de outrem. Eis o que acontece sem tirar nem pôr aos escravos. (Zeldin, 1996, p.14).

Esta consideração “objetal” do ser humano é semelhante ao que se passa com a psicopatologia. $\mathrm{O}$ ser-doente passa a ser "um doente" e, como tal, diverso dos demais. Continuemos com o tema da escravidão.

A escravidão perdura ainda em tempos atuais em três países africanos, a prática da escravidão ainda é tolerada, em nome de antigas tradições: Gana, Mauritânia e Sudão. Na Mauritânia, por exemplo, apesar de oficialmente abolida pela última vez em 1981, existe a subjugação dos haratines, uma casta de escravos negros há gerações, pela minoria berbere - e perdura ainda, num outro sentido, metafórico e mais amplo; por exemplo, quando o ser humano se torna escravo de suas paixões, de seu trabalho ou mesmo de hábitos, ideologias e estruturas dos quais não consegue se desvencilhar.

Segundo Zeldin (1996), os seres humanos se escravizaram no passado por três razões. Em primeiro lugar, pelo "medo", o que fez com que muitos concordassem com o menosprezo e a humilhação. "O medo tem sido quase mais poderoso que o desejo de liberdade" (Zeldin, 1996, p. 15). Isto é de fato real, quando observamos nossas próprias dificuldades em entrar em contato com nossos sentimentos. Fica a pergunta: quantas vezes, em nossas vidas, o medo não nos paralisou a ponto de nos colocarmos em situações tais que posteriormente nos arrependemos?, ou quanto o medo nos impele a sermos escravos de nossas "paixões" ou de um outro que nos é significativo? Ao final, temos que "os violentos têm sido mais vitoriosos ao longo da história porque administram o medo com que cada um de nós nasce" (Zeldin, 1996, p.15). E pensar na naturalidade do medo...

Em segundo lugar, temos a "escravidão voluntária". Esta é produto do "desespero", da falta de horizontes e da crença na impossibilidade de saída. Conta-se que, entre os séculos XV e XVIII, algo em torno de um décimo dos moscovitas tinha se tornado escravo. Esta situação já foi comparada à dos 
americanos pobres que vivem do seguro social. Além disso, “... nem todo escravo sonha com a liberdade. Após alguns anos de total dominação, uma existência independente na dura realidade torna-se quase inimaginável" (Zeldin, 1996, p.15). Em situações semelhantes, uma vez que uma instituição está criada - a escravidão -, mesmo aqueles que sofrem com ela encontram modos de exploração que auxiliam na perpetuação desta mesma instituição. Isto nos lembra sobremaneira os modos de sustentação patológicos de determinadas estruturas familiares, ou mesmo o chamado "benefício secundário da doença". Este é um exemplo claro do que comumente denominamos "alienação".

Podemos destacar algumas curiosidades a respeito da escravidão. Na dinastia Han, da antiga China, a palavra "escravo" era derivada da palavra "criança" ou "esposa e criança". Antes de se escravizarem os africanos, os primeiros a serem escravos foram os eslavos que, inclusive, deram nome à escravidão (slavs, slaves). Eslavo chegou mesmo a significar "estrangeiro". Ainda sobre isto, a palavra russa para "trabalho" (rabota), deriva da palavra "escravo" ( $r a b)$. Mesmo em nossa cultura, esta correlação entre trabalho e sofrimento encontra eco. Basta, para tanto, relembramos o Gênesis. Etimologicamente, "trabalho", em nossa língua, deriva de tripalium, um instrumento de tortura. Da idéia inicial de "sofrer", passou-se à idéia de "lutar", "esforçar-se" e, por fim, "pugnar" (Cunha, 1991).

O terceiro tipo de escravidão é aquele ancestral do atual executivo ou burocrata. Boa parte da manutenção dos impérios otomano e chinês se deu pelas mãos dos escravos; às vezes, escravos comuns, que mesmo assim ascendiam a altos postos. Têm-se notícias de escravos que se tornaram grão-vizires ou mesmo imperadores. Isto foi produto de um ideário hedonista na antiguidade, ou se preferirem, está na origem da sociedade do lazer, onde o sonho é viver como senhor, sem labuta. Isto gera um movimento interessante: é muito comum haver grande relutância em sabandonar condutas "escravas" e a dependência em si - que tanto pode ser em relação a uma pessoa como a um grupo social, ou mesmo a uma idéia ou uma ideologia (muito do amor romântico está baseado neste tipo de dependência).

Muitos logravam assegurar sua autonomia mesmo sendo forçados a trabalho braçal, fingindo aceitar as humilhações, fazendo uma representação, de forma a que o senhor vivesse na ilusão de que detinha o comando, embora eles, os escravos, soubessem que ele, o senhor, deles dependia (Zeldin, 1996, p.17).

Isto fica explícito num provérbio de escravos jamaicanos que diz: "Passe por tolo para obter vantagen".

Com certeza a solução para isto não é simplesmente a abolição da escravatura, dado que esta ressurge com outras roupagens. Atualmente podemos pensar em nossa suprema escravidão da tecnologia ou, pior, da sabedoria alheia. E por que isto permanece? Porque é doloroso, é cansativo, é laborioso ser livre. A liberdade não é um estado de espírito, mas uma condição humana; e como tal, ela não pode "ser" conquistada, mas deve "estar sendo" continuamente conquistada. Como bem assinala Zeldin (1996), a questão da liberdade não se resume a direitos ou a leis.

Estamos, no final das contas, falando da importância dos nossos encontros e dos nossos desencontros. "Ocorre um desperdício de oportunidades sempre que um encontro se realiza e nada acontece.. O ruído do mundo é feito de silêncios" (Zeldin, 1996, p.18).

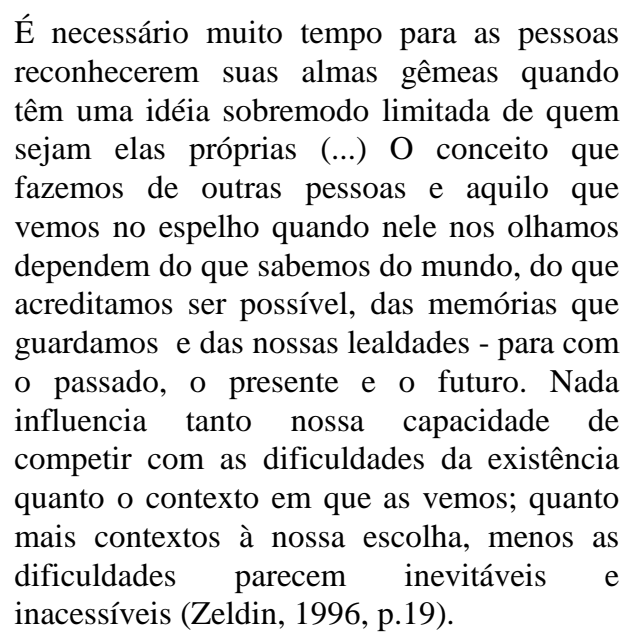

Estes parecem ser os problemas centrais também referentes ao fenômeno psicopatológico, os quais reverberam nesta questão: o "reconhecimento" e a "perspectiva". Nós nos escravizamos para termos perspectivas de sobrevivência, adoecemos por necessidade de reconhecimento, de encontro. Do reconhecimento obtém-se a possibilidade e a realidade; e da perspectiva tomamos as soluções para as adversidades. Velhas maneiras de pensar são muitas vezes responsáveis pela manutenção das pessoas em determinados estados ou mesmo responsáveis pela noção errônea de impossibilidade ou de fatalidade.

Mudar mentalidades é impossível, dado que estas se fundamentam em memórias e em experiências que 
são inextinguíveis. Todavia, ampliar horizontes é expandir memórias e, assim, aumentar as possibilidades de mudança e diminuir as repetições de erros.

\begin{abstract}
Quando as pessoas olham além de seus arredores familiares, quando aprendem a ler e a viajar, descobrem que muitos indivíduos estranhos compartilham de suas emoções e interesses (Todorov, s/d, p.296).
\end{abstract}

Quando observamos atentamente a diversidade, encontramos a similaridade. E o sentimento de estranheza diante da situação se esvai com a complementaridade, com o reconhecimento e a ampliação da visão: das turvas brumas da ignorância à luminosa expectativa da possibilidade. Reconhecimento e perspectiva.

A questão do patológico invariavelmente esbarra nesta questão da diversidade. E um dos melhores exemplos disto é o exótico. "Exótico" é sinônimo de "estranho", "estrangeiro", "esquisito"; designa aquilo que não pertence a um determinado grupo ${ }^{2}$. No francês antigo - do qual parte a palavra em nossa língua (Cunha, 1991) - designava aquilo que não fazia parte da civilização ocidental, ou seja, era relativo ao que derivava de países longínquos. ${ }^{3}$ Representa aquilo que varia e que difere do considerado como o "mesmo". Nesta perspectiva, ao mesmo tempo em que "afasta", "aproxima", atrai - exatamente pelo fato de ser diverso.

Para Tzvetan Todorov (s/d), o exótico é, antes de tudo, um relativismo. Para ele, o exotismo é um excelente exemplo de como "o outro é sistematicamente preferido ao mesmo", e como se trata "menos de uma valorização do outro do que uma crítica de si, e menos a descrição de um real do que a formulação de um ideal" (Todorov, s/d, p.297). Estamos diante de um paradoxo de nossa realidade: o exótico tanto é alvo da escravidão quanto é preferido ao cotidiano.

Esta última consideração, a valorização do exótico - como um preferido à situação - é constantemente relevada na história e na literatura. Observemos a "regra de Homero": o país mais distante é o melhor. Aliado a isto, temos que, para o

2 Como apontado anteriormente, podemos fazer uma associação entre o "exótico" e o "escravo. Não se costuma escravizar um "semelhante". Aquele "semelhante" que se torna escravo, reflete na verdade uma consideração divergente: deixa de ser considerado como um "mesmo", para ser um "diferente".

3 Segundo o Petit Robert (Dictionnaire de la Langue Française), o termo "exotisme" era raro até o século XVIII. papel de ideal exótico, sempre encontramos os povos ou as culturas mais distantes e mais ignoradas. Isto se explica pelo fato que:

(...) o conhecimento é incompatível com o exótico, mas o desconhecimento é, por sua vez, inconciliável com o elogio dos outros; ora, é precisamente o que o exotismo desejaria ser, um elogio no desconhecimento. Este é seu paradoxo constitutivo (Todorov, s/d, p.298).

O exótico evoca invariavelmente uma mitologia, chamada "época de ouro", refletindo um passado paradisíaco perdido e distante. O exotismo vem sempre na consideração de uma dupla simetria, segundo a qual os povos e as culturas consideradas exóticas são ou mais simples ou mais complexos do que a nossa, sendo mais "naturais" ou mais "artificiais", etc. Em outras palavras, a interpretação do "exótico" é, invariavelmente, polarizada.

A interpretação primitivista do exotismo é tão antiga quanto a própria história. Todavia, encontra sua maior difusão a partir das grandes viagens do século XVI, o chamado período das "grandes descobertas", em particular dada a descoberta da América pelos europeus, onde estes encontram um imenso terreno para projeções de um ideário de ouro.

Um dos principais pontos que caracterizam esta situação é a identificação dos modos "selvagens" com os dos antepassados. Este dado é particularmente importante, pois as culturas em geral, e mais fortemente, a européia, tendem a valorizar o seu passado como um momento perdido de "plenitude e harmonia", enquanto o presente é encarado como uma "queda". A esta consideração imaginária, idealizada, romântica e luminosa do momento - comum a todos nós - denominamos de passé glorieux.

Não é necessário procurar muito por exemplos desta situação. Podemos citar os romances cavalheirescos ou os filmes de época, permeados por imagens heróicas e sublimes. Segundo Todorov, esta idealização dos selvagens se inicia com as primeiras relações de viagem. E cita particularmente Cristóvão Colombo e Américo Vespúcio, este último, um dos principais precursores dos quadros dos "bons selvagens", a partir de suas descrições dos hábitos indígenas.

A sociedade dos selvagens, a partir de Américo, se caracteriza por cinco traços: inexistência de vestuário; inexistência de propriedade privada; inexistência de hierarquia ou subordinação; inexistência de interdições sexuais; inexistência de religião; 
tudo se resumindo nesta fórmula: viver segundo a natureza (Todorov, s/d, p.300).

Ainda segundo Todorov, esta descrição de Américo Vespúcio serviu de inspiração para Thomas Morus escrever a sua Utopia. ${ }^{4}$ A imagem do "bom selvagem" é ainda complementada pelo trabalho de Jean de Léry. Sua obra, Histoire d'un Voyage en la terre du Brésil, serve como meio de crítica social: Léry prefere os canibais aos maus cristãos.

A "idade de ouro" ou o passé glorieux designa que, originalmente, o homem era mais natural (e, portanto, mais "saudável") - e o exemplo mais significativo de um comportamento "natural" é a sexualidade -, e com o passar do tempo, tornou-se cada vez mais artificial. Quiçá a "loucura" em si possa ser associada a esta idéia; afinal, embora o conceito de loucura mude de acordo com as épocas, é histórico o fato de haver, em determinado momento, uma inserção maior do patológico no seio do social.

Este naturalismo perdido é muitas vezes o responsável por uma consideração estigmatizante e desestruturante. Basta passarmos os olhos pela obra de Foucault para constatarmos a realidade histórica da loucura (Foucault, 1991). Boa parte - ou talvez a maior parte - da consideração do patológico passa por uma desconsideração: tanto da loucura quanto do sentido vivencial desta loucura.

A imagem do "bom selvagem" desempenha um papel importante no período compreendido entre os séculos XVI e XVIII, sendo particularmente presente nas relações de viagem, um gênero literário então em ascensão. Esta época coincide, em parte, com o período no qual a loucura passou a ser objeto de exclusão, como aponta Foucault (1984).

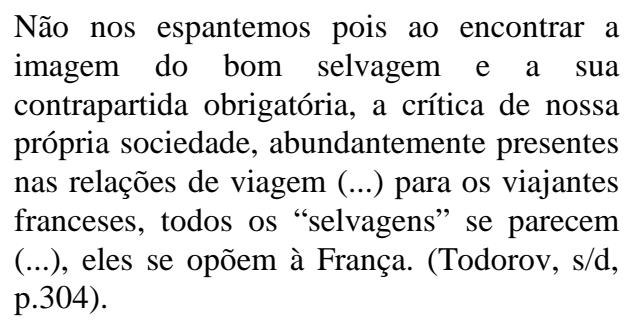

Associa-se tradicionalmente o pensamento de Jean-Jacques Rousseau ao primitivismo e à idéia do "bom selvagem". $\mathrm{Na}$ realidade ele foi um dos mais vigilantes críticos desta posição. Mesmo assim, a

4 A palavra "utopia" designa um lugar imaginário ou algo irrealizável. É uma fantasia, proposta por Thomas Morus (1478-1535) e publicada em 1516, que formou o vocábulo a partir do grego óu ("não") e tópos ("lugar"), ou seja, "lugar nenhum" (Cunha, 1991). partir do uso impreciso de algumas de suas próprias noções, Rousseau foi o responsável pela confusão gerada em seus primeiros leitores. Rousseau opõe o "homem da natureza" ao "homem civil", revelando sua preferência pelo primeiro.

\begin{abstract}
Mas esta imagem é demasiado simplista, e isto por diversas razões. Primeiramente, o estado da natureza (e portanto, o homem da natureza, no sentido do termo) não corresponde, para Rousseau, a um período real da história da humanidade, mais ou menos distanciado de nós (...). Esta noção é uma construção do espírito, uma ficção destinada a nos facilitar a compreensão dos fatos reais, não um "fato" comparável aos outros. (Todorov, s/d, p.310).
\end{abstract}

Uma vez no "estado da sociedade", o homem não pode retornar ao "estado da natureza". Além disso, entre o estado primitivo e a perfeição, Rousseau escolhe a segunda. Para ele, "O puro estado de natureza é aquele de todos onde os homens seriam o menos incômodos, mais felizes, e em maior número sobre a terra" (Rousseau, citado por Todorov, s/d, p.311-312).

A questão da corrupção social, para Rousseau, se explica pelo fato de que em sua visão de história, a sociedade realmente corrompe o homem, mas o homem somente se torna corrompido quando entra em sociedade, o que delimita um paradoxo. Entre o estado da natureza e o estado de sociedade, existe um intermediário, onde o homem não é mais um animal e ainda não é o miserável que se tornará; é o "estado selvagem", e é neste estado que a humanidade constitui a sua maior felicidade.

\section{DIVERSIDADE, EXCLUSÃO E PSICOPATOLOGIA}

Voltando à questão do exótico, temos que uma característica extremamente importante de sua descrição é que, para se idealizar uma sociedade, não é conveniente descrevê-la muito de perto. Ao mesmo tempo, uma descrição pouco detalhada, por seu turno, se presta, pouco à idealização (Todorov, s/d).

A descrição dos estados psicopatológicos vai na mesma direção. Basta retomarmos a crítica de Thomas Szasz (1978) principalmente no seu livro Esquizofrenia. O Símbolo Sagrado da Psiquiatria. Neste, Szasz aponta a esquizofrenia como um símbolo de reverência que se tornou a marca da ortodoxia psiquiátrica. A descrição da "loucura" é, em geral, rica 
de detalhes, mas objeto de uma avaliação distanciada: a "loucura" está no outro e o outro me é divergente.

Chamar a atenção para uma aproximação ao patológico implica numa "desidealização" da loucura. Implica em encontrarmos o caos subjetivo e, a partir deste, a similaridade e a complementaridade.

Denis Diderot, no século XVIII, ao descrever o selvagem taitiano, emprega expressões tais como "inocente" e "feliz" para os selvagens, enquanto os civilizados seriam "corrompidos", "vis" e "infelizes". Não é incomum este tipo de idealização e polarização ser associada ao patológico. A histeria já foi largamente comparada com "frescuras", enquanto a depressão já foi "coisa de quem não tem o que fazer", ou seja, quem trabalha não adoece. A rigor, o "estar" patológico tem sido continuamente associado a uma "desresponsabilização" diante da realidade, das regras sociais, etc.

Uma idealização romântica também já foi moda no terreno da consideração do "patológico": para alguns, o "louco" estaria mais próximo do espiritual do que o homem comum, que permaneceria preso nas teias do materialismo e da civilização. Não esqueçamos que o processo civilizatório já foi considerado produto da repressão sexual. Por outro lado, o louco seria "feliz", pois não teria com que se preocupar. Romantismos à parte, a idealização serve para distanciar-nos de nossas próprias identificações. Serve ainda para dissociar o sofrimento, polarizandoo, evitando-o, e delimitando um "contexto" ou uma "situação" da qual fazemos parte, sem que nos caiba responsabilidade sobre ela. Aproximar-se da patologia, descrevê-la na sua totalidade, encará-la como uma realidade, implica em encarar o sofrimento humano - não como objeto alheio a nós, mas como realidade concreta - na sua clareza e na sua mais profunda crueza.

Se atentarmos para uma "história da loucura", veremos que, a partir de meados do século XVII, o mundo da loucura passou a ser o "mundo da exclusão" (Foucault, 1984, 1991) e, conseqüentemente, da "alienação".

Criam-se (e isto em toda a Europa) estabelecimentos para internação que não são simplesmente destinados a receber os loucos, mas toda uma série de indivíduos bastante diferentes uns dos outros, pelo menos segundo nossos critérios de percepção: encerram-se os inválidos pobres, os velhos na miséria, os mendigos, os desempregados opiniáticos, os portadores de doenças venéreas, libertinos de toda espécie, pessoas a quem a família ou o poder real querem evitar um castigo público, pais de família dissipadores, eclesiásticos em infração, em resumo, todos aqueles que, em relação à ordem da razão, da moral e da sociedade, dão mostras de 'alteração'(Foucault, 1984, p.78).

Mais um exemplo da segregação do diverso. E Foucault continua:
A loucura no sentido mais amplo, situa-se aí: neste nível de sedimentação nos fenômenos de cultura em que começa a valorização negativa do que tinha sido apreendido originalmente como o Diferente, o Insano, a Desrazão (Foucault, 1984, p.89).

Os manicômios - que surgem efetivamente no ocaso da Idade Média, a partir da conversão dos antigos leprosários - representam um exemplo claro dos "rituais de exclusão", que alienam os "diferentes" ou "indesejáveis", ou ainda os "perturbadores", através de uma separação geográfica, colocando os loucos fora do campo visual e interacional da sociedade, tal como os asilos e as prisões (Goffman, 1996) e fazendo com que os "homens de bem" não sofram com uma convivência inadequada ${ }^{5}$. Outros rituais são a separação material - através do internamento - ou a "separação virtual", como no começo do século XVII na Europa (Foucault, 1984).

Existe uma tradição no pensamento ocidental de busca das "causas" ou das "condições de surgimento" de um determinado evento ou ocorrência. Seria algo como a eterna busca do determinante. No caso da psicopatologia não poderia ser diferente. Todavia, isto se constitui num erro, dado que as condições promotoras, desencadeadoras ou determinantes dos eventos ou da própria realidade são múltiplas e precisam ser circunstancializadas. Na realidade, este erro é estabelecido pelo império da linearidade no pensamento ocidental. Corroborando isto, podemos lançar mão de algumas idéias de Foucault sobre o tema:

O erro seria crer que a evolução orgânica, a história psicológica, ou a situação, do homem no mundo pudessem revelar estas condições. (Foucault, 1984, p.71).

\footnotetext{
Este nível de alienação não está distanciado do nosso cotidiano. Basta lembrarmos o velho ditado "dize-me com quem andas que te direi quem és", para justificar outros "rituais de exclusão", seja na família, na escola, no trabalho ou na comunidade. Os bolsões de pobreza das grandes cidades são exemplos típicos, e a alienação é acompanhada do estigma.
} 
Émile Durkheim assinala, sobre a relatividade do patológico, que seriam considerados patológicos aqueles fenômenos que, ao se afastarem da média, tanto marcassem as etapas superadas por uma evolução quanto anunciassem as etapas subsequentes que ainda não estivessem esboçadas.

Ainda, segundo Foucault (1994), as concepções dos antropólogos americanos não seriam muito distintas das de Durkheim.

Cada cultura, segundo Ruth Benedict, elegeria algumas das virtualidades que formam a constelação antropológica do homem (...) Daí cada cultura formará de doença uma imagem cujo perfil é delineado pelo conjunto das virtualidades antropológicas que ela negligencia ou reprime (Foucault, 1984, p.72).

Assim, as diferenças vão sendo acentuadas e serão aceitas ou negligenciadas a partir das estruturas sociais nas se quais encontram alicerçadas. Se, numa cultura, como a dos índios Crow, por exemplo, se valorizam as condutas agressivas, as virtudes intelectuais levarão o indivíduo a ser considerado um "doente" ou um "incapaz".

Nestas concepções antropológicas, a doença é encarada a partir de seus aspectos negativos e virtuais. É negativa por estar associada a uma média, uma norma, um padrão, ou seja, a partir disto, uma doença seria naturalmente marginal ${ }^{6}$; e é virtual, dado que seu conteúdo seria definido pelas possibilidades. Para Durkheim, por exemplo, estas possibilidades se manifestam como uma "virtualidade estatística" no sentido de um desvio em relação a uma média, e no caso de Ruth Benedict, seria uma "virtualidade antropológica da essência humana" (Foucault, 1984).

Esta "aversão" ao patológico - representativa desta polaridade similaridade/diversidade -, a qual acreditamos ser produto de um ideário fantasmático que poderíamos denominar de angústia do paraíso perdido, de saudosismo do passé glorieux e que levaria a uma mitologização da saúde como um "éden" platônico, se inscreve numa tradição cultural:

(...) nossa sociedade não quer reconhecer-se no doente que ela persegue ou que encerra; no instante mesmo em que ela diagnostica a doença, exclui o doente. As análises de nossos psicólogos e sociólogos, que fazem do doente um desviado e que procuram a origem do mórbido no anormal, são, então,

6 Em oposição a "positiva" ou que afirma a partir do próprio fenômeno. antes de tudo, uma projeção de temas culturais. $\mathrm{Na}$ realidade, uma sociedade se exprime positivamente nas doenças mentais que manifestam seus membros... (Foucault, 1984, p.74).

Outro elemento que sempre esteve associado de perto com a questão da psicopatologia é a religião. Desde os primórdios - e em especial, nos primórdios nas sociedades xamânicas, o "louco" era visto como o veículo de comunicação com a divindade. Em outras palavras, a loucura não somente é privilegiada, como tem a sua função social e religiosa dentro da sua comunidade. Podemos conjeturar com isto que a exclusão nasce no momento em que se "desfuncionaliza" a loucura, ou seja, no momento em que ela não mais consegue manter o seu espaço funcional na estrutura social. A Igreja e a economia burguesa são, neste sentido, autênticos algozes da loucura.

Foi numa época recente que o Ocidente concedeu à loucura um status de doença mental. Afirmou-se, afirmou-se até demais que o louco era considerado um 'possuído'. E todas as histórias da psiquiatria até então quiseram mostrar no louco da Idade Média e do Renascimento um doente ignorado, preso no interior da rede rigorosa de significações religiosas e mágicas. Assim, teria sido necessário esperar a objetividade de um olhar médico sereno e finalmente científico para descobrir a deterioração da natureza lá onde se decifravam apenas perversões sobrenaturais. (Foucault, 1984, p.75).

A medicina, por duas vezes, foi usada para intervir no problema da possessão. Pela primeira vez, entre 1560 e 1640, contra certas ordens monásticas; e na segunda, entre 1680 e 1740 , por solicitação da própria Igreja, contra o misticismo protestante e jansenista. Estas passagens servem para ilustrar a estreita relação entre patologia e religião, e para exemplificar os modos de apropriação do "diverso" no seio de uma sociedade.

Como segue afirmando Foucault, antes do século XIX, o status da loucura era polimórfico. Desde a Grécia antiga, uma parte da loucura já continha noções de patologia. Em fins do século XV, contudo, percebe-se uma renovação da loucura a partir da linguagem. Retrata-se, principalmente na literatura, o "pavor da morte e da loucura". A todo canto temos festas populares com espetáculos associados à loucura, tais como o Navio Azul em Flandres, a Nave dos Loucos de Bosch ou Margot, a Louca, bem como 
textos que se tornaram clássicos como a Stultifera navis de Brant ou o Elogio da Loucura de Erasmo de Rotterdam.

Foi ainda no século XV que surgiram os primeiros locais especificamente destinados aos loucos, onde receberiam "tratamento". Ainda assim, estas práticas eram isoladas; no geral, a loucura permanecia em "estado livre, ou seja, ela circula, faz parte do cenário e da linguagem comuns, é para cada um uma experiência cotidiana que se procura mais exaltar do que dominar" (Foucault, 1984, p.75).

Neste período - talvez pudéssemos chamá-lo de "romântico" - havia uma grande tolerância e aceitação social à loucura; há mesmo "loucos célebres" que escrevem "obras de loucura" (sobre isto, Foucault cita, por exemplo, Bluet d'Arbère).

Já a partir da metade do século XVII, a loucura deixa o mundo romântico para penetrar no mundo da "exclusão". Criam-se, ou melhor, aproveitam-se os leprosários para estabelecer as instituições de "cuidados" para os loucos.

$\mathrm{Na}$ França, cada grande cidade possuía um hospital de loucos. Estes não tinham "vocação" médica, ou seja, a admissão não derivaria da doença e, portanto, desembocava num tratamento; mas acolhia-se o louco a partir da incapacidade da sociedade de contê-lo ou mantêlo. Em alguns hospitais, era comum o trabalho forçado. Esta dimensão necessária do labor também refletia uma estrutura socioeconômica na qual estava calcada a loucura, e que, por se associar ao modus operandi da sociedade burguesa e da constituição das estruturas econômicas, valorizava a produção e abominava a ociosidade. Podemos especular que esta foi uma das mais significativas razões que levaram à segregação dos "diferentes" ou melhor, daqueles que não produziam de acordo com a norma imposta pela moderna sociedade industrializada. Os loucos eram, assim, excluídos, não propriamente devido à sua doença - que poderia e deveria ser objeto de atenção - mas devido à sua incapacidade de responder adequadamente às demandas externas e de tomar parte da estrutura de produção da sociedade. A internação e o confinamento dos loucos nos hospitais gerais resultaria, segundo Foucault (1984), numa "reestruturação do espaço social".

As internações cumprem, assim, uma função de silenciamento e afastamento da loucura no seio da civilização "normal". Todavia, logo cedo esta função se perde, a partir de meados do século XVIII, quando renasce a inquietude e ressurge o louco nos cenários sociais. Um bom exemplo disto é a obra de Denis Diderot, intitulada Le Neveu de Rameau. Paulatinamente, a partir da reforma francesa de 1789 , foi-se exigindo que os hospitais de loucos fossem destinados "apenas para os loucos". A partir daí, as internações ganham um caráter médico, primordialmente através de Philippe Pinel na França, William Tuke na Inglaterra e Wagnitz e Reil na Alemanha. E, como ressalta Foucault, em relação a estes nomes, descobre-se neles a simbologia do advento do "humanismo" e de uma "ciência finalmente positiva".

Não obstante, as coisas não caminharam como desejado. A medicina contemporânea, ao invés de romper com as estratégias antigas de relação com a loucura, estreitou-as em torno do "louco". "Curar" passa a ser sinônimo de assumir culpa e dependência.

Pinel, em Bicêtre (...) reconstituiu em torno deles todo um encadeamento moral, que transformava o asilo numa espécie de instância perpétua de julgamento: o louco tinha que ser vigiado nos seus gestos, rebaixado nas suas pretensões, contradito no seu delírio, ridicularizado nos seus erros: a sanção tinha que seguir imediatamente qualquer desvio em relação a uma conduta normal. E isto sob a direção do médico(...) (Foucault, 1984, p.82).

Era comum o uso de instrumentos ou técnicas que obrigavam os pacientes a confessar a ilusão de suas crenças (semelhante aos antigos métodos da Inquisição): desde duchas geladas sobre a cabeça, até máquinas rotatórias ou gaiolas móveis, tudo é passível de ser empregado em prol da "cura" da loucura. Refletindo sobre isto, não mais nos surpreendemos com o título do livro de Erving Goffman (1996), Manicômios, Prisões e Conventos.

A partir deste momento, a loucura deixa de ser um fenômeno global, relativo a problemas seja da imaginação, seja do corpo ou da alma, para ser entendida como manifestação da interioridade, movimento da culpa e da liberdade, recebendo assim, o status de estrutura psicológica. Torna-se a "experiência da Desrazão".

Neste ponto Foucault chega ao impasse da atualidade:

Nunca a psicologia poderá dizer a verdade sobre a loucura, já que é esta que detém a verdade da psicologia (...). Levada até sua raiz, a psicologia da loucura seria não o domínio da doença mental e consequentemente a possibilidade de seu desaparecimento, mas a destruição da própria psicologia e o reaparecimento desta relação essencial, não psicológica porque não moralizável, que é a relação da razão com a desrazão. (Foucault, 1984, p.85-86). 
O impasse resulta da dialética na compreensão da loucura, entre razão e desrazão. Talvez Foucault esteja certo ao afirmar que é a loucura a real detentora da verdade da psicologia. Talvez tenhamos que efetivamente retomar o diálogo direto com a loucura, tal qual Erasmo e, assim, encontrarmo-nos com ela em nós mesmos, dado que ela é justamente a "única capaz de alegrar aos deuses e os mortais" (Erasmo de Rotterdam, 1988, p.7). Talvez seja na afirmação da loucura que encontremos o real caminho da cura, como podemos observar em numerosos discursos de "loucos".

Talvez pudéssemos afirmar, com isto, a ironia da loucura, quando as "verdades" incômodas são postas na boca do "louco" (como temos em Erasmo); o paradoxo da loucura, tal qual o profeta Zaratustra, de Nietzsche, tomado por louco pela multidão; ou mesmo o patético da loucura, quando o louco se torna conveniente ao alienista (como no conto machadiano).

De qualquer modo, ficamos com a impressão de que a compreensão, ou mesmo a explicação do fenômeno psicopatológico, perpassam a consideração de um sentido de totalidade deste, enquanto um fenômeno histórico, social, psicológico, econômico, cultural, biológico, individual, grupal, etc.

Parece-nos necessário perceber a questão do patológico a partir de uma relação afastamentoaproximação, tanto do outro quanto de si mesmo, numa relação igualmente dialética que perpassa a consideração do "mesmo", da "similitude" daquela loucura que nos é "alheia", para percebê-la não mais como distanciada pela "diversidade", que tanto atrai quanto rechaça, mas como uma manifestação do humano presente em mim e no "outro".

O "exótico", o "diverso", na sua consideração polarizada, refletida em constatações tão humanas e tão cruéis como a escravidão, podem ser sinais das possíveis considerações limitadas que fazemos do mundo humano: o mundo que é do "outro", quando não o aproximamos do nosso mundo.

Quiçá desta maneira possamos resgatar a complexidade do sentido da loucura.

\section{REFERÊNCIAS BIBLIOGRÁFICAS}

Binswanger, L. (1971). Introduction à l'Analyse Existentielle. Paris: :Les Éditions de Minuit (Original em alemão de 1947).
Binswanger, L. (1977). Três Formas de Existência Malograda. Rio de Janeiro: Zahar Editores. (Original em alemão de 1956).

Bonin, W.F. (1991). Diccionario de los Grandes Psicólogos. Mexico: Fondo de Cultura Económica.

Coleman, J.C. (1977). Psicopatologia. Los Grandes Modelos Teóricos. Buenos Aires: Editorial Paidós.

Corsini, R.J. (1984). Encyclopedia of Psychology. (4 Vols.). New York: John Wiley \& Sons.

Cunha, A.G.da (1991). Dicionário Etimológico da Língua Portuguesa. São Paulo: Nova Fronteira.

Erasmo de Rotterdam (1988). Elogio da Loucura. São Paulo: Nova Cultural. (Coleção Os Pensadores)

Ey, H.; Bernard, P. \&Brisset, C. (1987). Manual de Psiquiatria. Rio de Janeiro: Masson/Atheneu .(Original de 1963).

Foucault, M. (1984). Doença Mental e Psicologia. Rio de Janeiro: Tempo Brasileiro.

Foucault, M. (1991). História da Loucura. São Paulo: Perspectiva.

Goffman, E. (1996). Manicômios, Prisões e Conventos. São Paulo: Perspectiva.

Ionescu, S. (1994). Catorce Enfoques de la Psicopatología. México: Fondo de Cultura Económica.

Jaspers, K. (1987). Psicopatologia Geral. (2 Vols.). Rio de Janeiro: Atheneu.

Minkowski, E. (1995). Le Temps Vécu. Paris: Presses Universitaires de France (Original de 1933).

Morel, P. (1997). Dicionário Biográfico Psi. Rio de Janeiro: Jorge Zahar Editor.

Paim, I. (1993). História da Psicopatologia, São Paulo: EPU

Sonnenreich, C. \& Bassitt, W. (1979). O Conceito de Psicopatologia, Distúrbio Psíquico, Doença, Anormalidade. São Paulo: Manole.

Szasz, T. (1978). Esquizofrenia: O Símbolo Sagrado da Psiquiatria. Rio de Janeiro: Zahar Editores.

Tizón, J.L. (1978). Introducción a la Epistemología de Psicopatología y la Psiquiatría. Barcelona: Editorial Ariel.

Todorov, T. (s/d). Nous et les Autres: La réflexion française sur la diversité humaine. Paris: Éditions du Seuil.

Van Den Berg, J.H. (1966). O Paciente Psiquiátrico: Esboço de psicopatologia fenomenológica. São Paulo: Editora Mestre Jou.

Zeldin, T. (1996). Uma História Íntima da Humanidade. São Paulo: Record.

Recebido em 07/12/2000

Revisado em 20/09/2001

Aceito em 30/09/2001 